\title{
Mengukur Tingkat Kinerja Tata Kelola Teknologi Informasi Di Perguruan Tinggi Menggunakan IT Balanced Scorecard
}

\author{
Reni Haerani \\ Program Studi Sistem Informasi Fakultas Teknologi Informasi Universitas Serang Raya \\ Jln. Raya Cilegon Serang KM. 5 - Taman Drangong Kota Serang \\ Renihaerani27@yahoo.com
}

\begin{abstract}
Abstrak - Salah satu tujuan utama tata kelola TI adalah untuk menyelaraskan setiap proses bisnis yang ada dengan teknologi informasi. Setiap institusi perguruan tinggi berusaha memanfaatkan TI sebagai alat untuk memenangkan persaingan bisnis tersebut. Agar TI dapat dimanfaatkan secara maksimal dan mendukung sistem yang ada di institusi perguruan tinggi, dibutuhkan penilaian kinerja dari TI secara berkala. Salah satu metode untuk melakukan penilaian terhadap kinerja tata kelola TI adalah dengan memanfaatkan IT Balanced Scorecard . Penilaian tata kelola dengan IT Balanced Scorecard diperlukan untuk melihat sejauh mana strategi tersebut terjalin, visi, misi dan tujuan yang ingin dicapai dalam institusi. Meningkatkan kinerja tata kelola TI adalah alasan utama untuk membangun dan menerapkan balanced scorecard tata kelola TI. Dengan balanced scorecard tata kelola TI , organisasi dapat memberdayakan jajaran struktural mereka, serta bisnis dan partisipan TI dengan memberikan informasi yang diperlukan untuk bertindak dan mencapai perpaduan yang lebih baik antara bisnis dan TI dan pada akhirnya mencapai hasil yang lebih baik. IT Balanced scorecard dapat memainkan peran penting dalam keseluruhan program yang harus tepat untuk meningkatkan tata kelola TI di institusi perguruan tinggi.
\end{abstract}

Kata Kunci : Tata Kelola TI, Tingkat Kinerja, IT Balanced Scorecard

\section{PENDAHULUAN}

Sebagai salah satu perguruan tinggi terkemuka, keberadaan suatu organisasi yang mengelola sistem dan Teknologi Informasi mutlak diperlukan. Unit ini akan menjadi penggerak utama pemanfaatan Teknologi Informasi dan sekaligus sebagai penentu kebijakan dan perencanaan, pengadaan, pengelolaan, dan pengevaluasian status system dan Teknologi Informasi. Beberapa hal yang menjadi alasan diperlukannya organisasi pengelola sumber daya informasi yang baik adalah :

1. Tingkat persaingan usaha yang semakin ketat dan bersifat global memerlukan adanya dukungan data dan informasi yang dapat diandalkan. Informasi akan dipergunakan para pengambil keputusan dan para pelaksana dalam menjalankan bisnisnya.

2. Pemanfaatan Teknologi Informasi yang tepat untuk keperluan operasional yang akan mampu menciptakan suatu penghalang (entry barrier) bagi masuknya pesaing usaha sejenis, terutama institusi pendidikan.

3. Pemanfaatan Teknologi Informasi yang tepat akan membuat stakeholders merasa senang terhadap perguruan tinggi ini. Diharapkan dengan adanya layanan jasa dengan Teknologi Informasi yang baik akan mampu menciptakan 'switching cost', sehingga masyarakat enggan beralih ke perguruan tinggi yang lain.

4. Adanya kenyataan bahwa keberadaan data yang tersebar di beberapa lokasi, jenis sistem dan Teknologi Informasi yang beragam, kualifikasi personil yang bermacam- macam menimbulkan permasalahan tersendiri dalam penerapan sistem dan Teknologi Informasi.

Berdasarkan hal tersebut diatas diperlukan adanya suatu tata kelola TI yang baik untuk mendukung kinerja organisasi pengelola sistem dan Teknologi Informasi yang memiliki karakteristik sebagai berikut :

1. Tingkat kepuasan stakeholder yang tinggi

2. Bersifat efektif terhadap biaya (cost effective)

3. Data terintegrasi dengan baik

4. Proses-proses yang efektif

5. Pelaksanaan komunikasi yang baik (komunikasi internal dan eksternal organisasi pengelola sistem dan Teknologi Informasi)

6. Memiliki ukuran-ukuran kinerja yang baik

7. Menerapkan proses Disaster Recovery

8. Biaya-biaya layanan terdokumentasi dengan baik

9. Mampu membuat perbandingan (benchmarking) produk dan jasa yang diberikan dengan perguruan tinggi lain yang sekelas.

Tata kelola TI merupakan bagian yang integral dari tata kelola perusahaan yang terdiri dari kepemimpinan dan struktur organisasi serta proses-proses, yang digunakan untuk memastikan bahwa TI perusahaan memelihara dan memperluas strategi dan sasaran perusahaan. Dalam hal ini, tata kelola TI menyediakan struktur yang menghubungkan proses-proses TI, sumber daya TI, dan informasi, dengan strategi dan dan sasaran perusahaan. Disamping itu, tata kelola TI juga mengintegrasikan dan menginstitusionalkan 
praktek-praktek terbaik dalam perencanaan dan pengorganisasian (planning and organizing), memperoleh dan mengimplementasikan (acquiring and implementing), menyediakan dan mendukung (delivering and supporting), serta memonitor dan mengevaluasi (monitoring and evaluating) unjuk kerja TI untuk memastikan bahwa informasi dan teknologi yang terkait mendukung sasaran bisnis.

Untuk mengukur kinerja perguruan tinggi berkaitan dengan tata kelola IT dapat dilakukan dengan Information Technology Balanced Scorecard (IT Balance Scorecard) yang merupakan suatu sistem manajemen, pengukuran dan pengendalian yang secara cepat, tepat dan komprehensif dapat memberikan pemahaman kepada pimpinan tentang potret dan pengembangan teknologi informasi diinstitusinya.

IT Balance Scorecard memiliki empat perspektif diantaranya, corporate contribution, customer orientation, operational excellence dan future orientation. Dengan penerapan IT Balance Scorecard kinerja institusi Perguruan Tinggi tidak hanya diukur dari keuntungan yang diperoleh secara finansial saja, sebagaimana yang selama ini kerap dilakukan, tapi juga mempertimbangkan proses internal serta kepuasan dan peningkatan kinerja pada setiap pegawai. Dengan demikian dapat dipastikan bahwa kinerja yang baik tidak hanya di masa sekarang ini akan tetapi juga di masa yang akan datang.

Dengan demikian, mengukur tingkat kinerja tata kelola TI menggunakan IT Balanced Scorecard akan memungkinkan organisasi/institusi mendapatkan keuntungan penuh dari informasi yang dimilikinya, sehingga memaksimalkan manfaat, mengkapitalisasi peluang dan mendapatkan keuntungan kompetitif . Tata kelola TI juga mengidentifikasi kelemahan kontrol dan menjamin adanya implementasi perbaikan yang dapat terukur secara efektif dan efisien.

\section{METODOLOGI PENELITIAN}

Area utama yang menjadi fokus Tata Kelola Teknologi Informasi :

1. Strategic Alignment, menghasilkan arah strategis TI dan penyelarasan TI dengan bisnis untuk mendukung pelayanan dan proyek.

2. Value Delivery, memastikan bahwa TI atau organisasi bisnis dirancang untuk mengendalikan secara penuh keuntungan TI untuk bisnis.

3. Risk Management, memastikan bahwa proses berjalan dengan seharusnya dan resiko dapat dikelola semestinya.

4. Resource Management, menghasilkan arahan umum dalam pengelolaan dan pemanfaatan sumber daya TI.

5. Performance Measurement, memantau pengukuran kinerja TI beserta kontribusi TI kedalam bisnis perusahaan.

Sedangkan menurut Forrester terdapat empat objective yang menentukan arah atau bentuk tata kelola TI. Setiap objective tersebut merupakan bagian dari tata kelola TI seperti pada gambar 2. Keempat objective itu terdiri dari (1) Accountability (bisa dipertanggung jawabkan), (2) IT value and alignment (Nilai-nilai TI) (3) Risk Management
(Pengelolaan Resiko), dan (4) Performance Measurement (Pengukuran Kinerja). Tata kelola TI bertujuan agar informasi yang dikelola bisa dipertanggungjawabkan, dan informasi yang dihasilkan benar-benar memberikan nilai tambah bagi proses bisnis yang ada pada organisasi. Dan resiko yang akan muncul berhubungan dengan TI bisa diminimalkan dan yang paling penting dari tata kelola TI adalah bisa mengukur kinerja dan dari pengimplementasian teknologi informasi tersebut.

Penjelasan dari setiap dimensi / objective tersebut adalah sebagai berikut :

1. IT value and alignment

Salah satu tujuan utama tata kelola TI adalah untuk menyesuaikan setiap unit bisnis dengan teknologi informasi. Dengan membuat struktur dan proses yang diperlukan dalam investasi teknologi informasi, pihak manajemen dapat memastikan bahwa investasi teknologi informasi yang dilakukan sesuai dengan strategi bisnis dan sesuai dengan urutan prioritas yang ada. Pada perencanaan ke depan, investasi teknologi informasi yang dilakukan diharapkan dapat tepat waktu, sesuai dengan dana yang dikeluarkan, dan memberikan nilai tambah sesuai dengan yang diharapkan. Peningkatan nilai tambah yang dimaksud antara lain pengurangan biaya, peningkatan pendapatan, mempercepat proses kerja, dan lain-lain.

2. Risk Management

Manajemen risiko pada teknologi informasi merupakan hal yang sangat penting . Risiko yang biasa dihadapi pada teknologi informasi antara lain risiko keamanan yang timbul dari serangan hacker, risiko privasi yang timbul dari pencurian identitas, pemulihan dari bencana, ketahanan system dari pemadaman dan risiko yang terkait dengan kegagalan proyek. Semua risiko yang mungkin dihadapi tersebut harus diantisipasi sehingga ketika risiko tersebut terjadi tidak menyebabkan kerugian yang fatal.

3. Accountability

Tata kelola TI bertujuan agar investasi pada teknologi informasi dapat dipertanggung jawabkan dan memberikan hasil sesuai yang diharapkan.

4. Performance measurement

Akuntabilitas dalam pengelolaan TI mensyaratkan untuk melakukan penilaian, biasanya dengan menerapkan balanced scorecard. Balanced Scorecard TI terdiri dari empat perspektif : IT Value, User, Operational Excellent, dan Future Orientation. Dua dari perspektif ini memuat pengukuran untuk dua tujuan utama tata kelola : IT Value dan manajemen risiko. Perspektif IT value berisi langkahlangkah spesifik untuk kesalarasan TI/bisnis dan IT value. Sedangkan perspektif Operational Excellence berisi langkah-langkah spesifik untuk mengelola risiko TI.

\section{HASIL DAN PEMBAHASAN}

Pengukuran kinerja dilakukan agar manajemen bisa memastikan seberapa baik TI bisa memberikan kontribusi pada keberlangsungan proses bisnis organisasi. Pengukuran kinerja TI biasanya didasarkan pada beberapa ukuran yaitu : 
a. Indikator Tujuan Kunci (Key Goal Indicator/ KGI)

b. Indikator Kinerja Kunci (Key Performance Indicator/ KPI)

c. Faktor Sukses Kritis (Critical Success Factor/CSF)

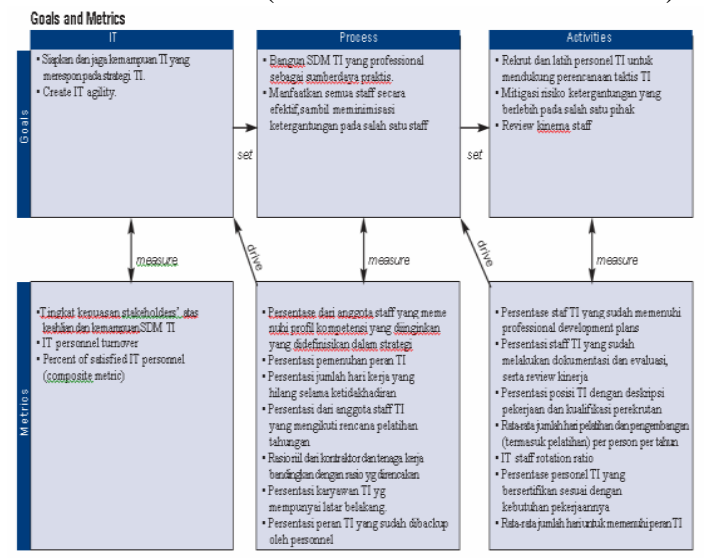

Gambar 1 Contoh Ukuran Kinerja TI pada PO7

Key Goal Indicator (KGI)

Mendefinisikan ukuran-ukuran yang akan disampaikan ke manajemen apakah suatu proses TI telah memenuhi persyaratan bisnis, biasanya ditentukan dengan kriteria informasi :

1. Ketersediaan informasi yang dibutuhkan untuk mendukung kebutuhan bisnis

2. Tidak adanya integritas dan risiko-risiko kerahasiaan informasi

3. Efisiensi biaya proses-proses dan operasional

4. Konfirmasi atas kehandalan, keefektifan dan ketaatan

\section{Key Performance Indicator (KPI)}

Mendefinisikan ukuran-ukuran untuk menerangkan seberapa baik proses TI dilaksanakan dan memungkinkan tujuan dicapai; merupakan indikator utama yang menentukan apakah tujuan bisa dicapai atau tidak, dan merupakan indikator yang bagus untuk penentuan kapabilitas, praktek-praktek dan keahlian-keahlian.

\section{Critical Success Factor (CSF)}

Merupakan kondisi-kondisi, kompetensi dan perilaku yang bersifat kritis terhadap keberhasilan pencpaian tujuan.

Contoh :

1. Sensitifitas terhadap kenyataan bahwa IT merupakan sesuatu yang terintegrasi dalam perusahaan dan bukan sesuatu yang hanya dianggap sebagai fungsi teknis.

2. Manajemen yang memiliki fokus dan informasi pada pelanggan, pasar dan proses internal

3. Kultur bisnis yang menghasilkan akuntabilitas, teamwork yang baik, memotivasi dilakukannya business improvement secara berkelanjutan dan perbaikan terhadap kesalahan.

\section{Balanced Scorecard}

Pengunaan balanced scorecard (BSC) telah menyebar luas sebagai pengukura kinerja dan sistem manajemen. Pendekatan
BSC telah diperkenalkan oleh Kaplan dan Norton pada tingkat perusahaan. Premis dasar mereka adalah bahwa evaluasi dari suatu perusahaan seharusnya tidak terbatas pada evaluasi keuangan tradisional tetapi harus dilengkapi dengan langkah-langkah mengenai kepuasan pelanggan, proses internal, pembelajaran dan pertumbuhan.

Hasil yang dicapai dengan menggunakan perspektif tambahan ini harus menjamin hasil keuangan masa depan dan mendorong organisasi menuju tujuan strategis sambil tetap menjaga keempat perspektif seimbang.

Untuk kerangka pengukuran keseimbangan ini, Kaplan dan Norton mengusulkan struktur tiga-lapis untuk masingmasing empat perspektif : misi, tujuan dan ukuran dari target yang harus ditetapkan dan inisiatif yang akan diluncurkan untuk mencapai tingkat yang lebih baik (Gambar 2).

Untuk memanfaatkan scorecard sebagai alat manajemen, scorecard harus ditambahkan dengan hubungan sebab akibat antara pengukuran. Hubungan ini digambarkan melalui dua jenis ukuran : ukuran hasil, dan faktor pendorong kinerja [Grembergen dan Haes, 2005]

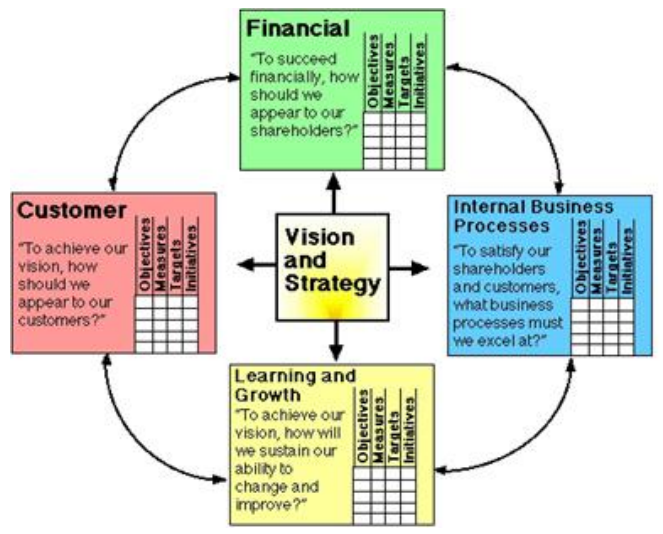

Gambar 2 Balanced Scorecard

(Sumber : balancedscorecard.org)

Konsep balanced scorecard kemudian diterapkan kepada fungsi teknologi informasi dan proses-prosesnya. Untuk TI sebagai penyedia layanan internal, keempat perspektif generik tersebut harus diubah agar sesuai dengan TI. Gambar 5 memperlihatkan perspektif balanced scorecard umum teknologi informasi untuk departemen TI.

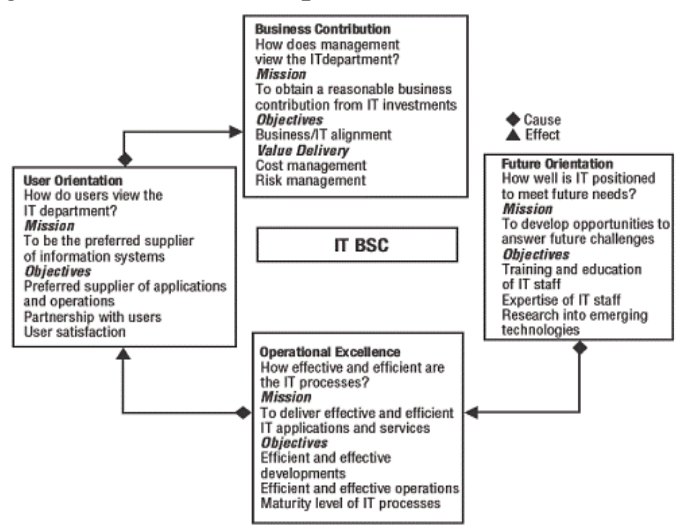

Gambar 3 IT Balanced Scorecard 
(Sumber : itgi.org)

IT Balanced Scorecard

IT Balanced Scorecard merupakan modifikasi atau penyelarasan dari Balanced Scorecard tradisioanl. Dimana seiring dengan intensifnya penggunaan TI di organisasi, maka unit TI yang mempunyai tugas kebutuhan internal perusahaan harus benar-benar mengimplementasikan sistem dan teknologi yang menunjang pencapaian strategi bisnis perusahaan.

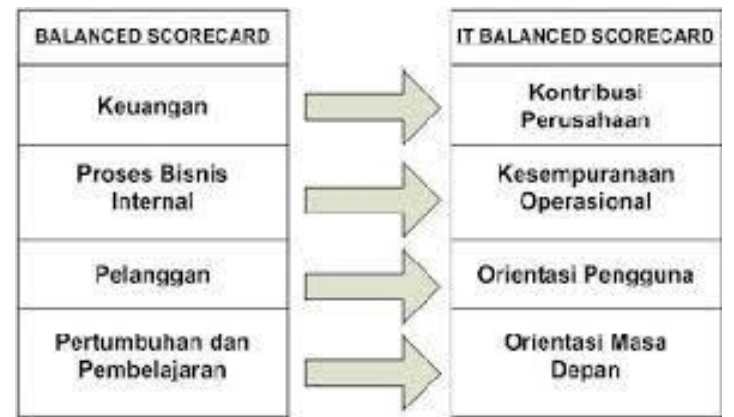

Gambar 4 Penyelarasan Perspektif BSC dan IT BSC

\section{KESIMPULAN}

Balanced Scorecard tata kelola teknologi informasi diperoleh dari gambaran balanced scorecard teknologi informasi dan balanced scorecard bagi dewan perusahaan. Tantangannya adalah untuk membangun sebuah scorecard yang dapat menangkap kinerja proses TI pengelolaan bersama dengan perbedaan IT BSC dan Board BSC.

Meningkatkan kinerja tata kelola TI adalah alasan utama untuk membangun dan menerapkan balanced scorecard tata kelola teknologi informasi. Harus jelas bahwa hanya mengukur saja tidaklah cukup; scorecard harus diimplementasikan sebagai sistem manajemen.

\section{REFERENSI}

[1] Craig Symons, Forrester, "ÏT Governance Framework, Best Practise", March 29, 2005

[2] Gold, R, S. 2003. Building The IT organization balanced scorecard. Information Systems Control Journal, 5, 4648.

[3] Gill, M. 2002 "Corporate Governance After Enron on World Com: Applying Principles of Results-based Governance" . Proceedings of Insight Conference on Corporate Governance, Calgary, Synergy Associates, Inc.

[4] Grembergen, W. V. and S. D. Haes , 2005 "Measuring and Improving Information Technology Governence through the Balanced Scorecard". University Antwerp Management School.

[5] ITGI, 2005, "Measuring and Demonstrating the Value of IT”, The IT Governance Institute, Rolling Meadows, IL, USA.

[6] Jogiyanto dan Wily Abdillah, 2011. Sistem Tata Kelola Teknologi Informasi. Yogyakarta : Penerbit Andi Offset.

[7] Keyes, J. 2005. Implementing the IT Balanced Scorecard : Aligning IT with corporate strategy, CRC Press.

[8] Norton dan Kaplan, 2000. The Strategy Focused Organization, Boston: Harvard Business School.

[9] Symons, C. 2005 "IT Governance Framework “, IT Governance Series, Forrester Research, Inc 